\title{
Lean Production as an Innovative Approach to Construction
}

\author{
Marcela Spišáková, Mária Kozlovská \\ Technical University of Košice \\ Civil Engineering Faculty, Institute of Construction Technology and Management \\ e-mail: marcela.spisakova@tuke.sk,maria.kozlovska@tuke.sk
}

\begin{abstract}
Lean production presents a new approach to the construction management which has enabled enterprises to attain very high levels of efficiency, competitiveness and flexibility in production systems. Nowadays, a number of industrial processes are managed in accordance with these advanced management principles [1]. The principles of lean production are applied within the integrated design and delivery solutions (IDDS) and prefabricated construction.

IDDS uses collaborative work processes and enhanced skills, with integrated data, information, and knowledge management to minimize structural and process inefficiencies and to enhance the value delivered during design, build, and operation, and across projects. Prefabrication presents a one of opportunities for construction methods, which allows the compliance with principles of sustainable design, provides the potential benefits such as faster construction, fewer housing defects, reduction in energy use and waste and elimination of environmental and safety risks.

This paper presents the lean production within the IDDS and its potential in the modern prefabrication. There is created a field providing of benefits of lean production in construction industry.
\end{abstract}

Key words: lean production, prefabrication, integrated design and delivery solutions (IDDS), construction industry

\section{Introduction}

The construction industry is under pressure to provide value for money, sustainable design and construction. On the other hand, this industry can and should be viewed as a manufacturing process for the realization of construction process. The construction process presents the transformation of construction material to structures through the construction sources - people, machinery and materials. The modern method of construction is based on the prefabrication and standardization of the construction elements with regard to specific customer requirements. We can say that the construction process is a manufacturing process, generally taking place at a specialized facility, in which various materials are joined to form a component part of a final installation [2]. Given this fact, it is possible to apply the principles of lean production during the realization of construction process. 


\section{Characteristic of lean production}

The journal „The Economist“ [3] describes lean production as a group of highly efficient manufacturing techniques developed (mainly by large Japanese companies) in the 1980's and early 1990's. Lean production was seen as the third step in an historical progression, which took industry from the age of the craftsman through the methods of mass production and into an era that combined the best of both. It has been described as ,the most fundamental change to occur since mass production was brought to full development by Henry Ford early in the 20th century".

In generally, lean production is an assembly-line methodology developed originally for Toyota and the manufacturing of automobiles. It is also known as the Toyota Production System or just-in-time production. Lean manufacturing (lean enterprise, lean production or simply, "Lean") is a production practice that considers the expenditure of resources for any goal other than the creation of value for the end customer to be wasteful, and thus a target for elimination. Working from the perspective of the customer who consumes a product or service, "value" is defined as any action or process that a customer would be willing to pay for. Essentially, lean is centred on preserving value with less work [4]. Lean manufacturing has been increasingly adopted as a potential solution for many organizations, particularly within the automotive and aerospace manufacturing industries [5].

The author Arbós [1] argues that lean production techniques have contributed to a spectacular improvement in efficiency, speed of response and flexibility in production at many industrial enterprises, through process-based management, elimination of waste and the highly flexible implementation of these processes. Lean management has allowed these enterprises to offer a highly diversified range of products, at the lowest cost, with high level of productivity, speed of delivery, minimum stock levels and optimum quality.

\subsection{Basic attributes of lean production}

The methods of lean production aim to combine the flexibility and quality of craftsmanship with the low costs of mass production. In lean-production systems a manufacturer's employees are organised in teams. Within each team a worker is expected to be able to do all the tasks required of the team. These tasks are less narrowly specialised than those demanded of the worker in a mass-production system, and this variety enables the worker to escape from the soul-destroying repetition of the pure assembly line.

Lean production is based on the following attributes:

- specification of elements which create a value for costumer (not for department or company),

- identification of all necessary steps for design, manufacture and supply of products (on the other hands, specification of activities which create no value for customer),

- focusing on the flow for creation of value without interruption, waiting and time delay,

- carry out activities only on demand of customer,

- focusing on the continuous removal of over-production sources. 
It follows that the lean production presents a technology that minimizing the wastes in the manufacturing process. In this process can be defined seven types of wastes [6]:

1. waste of over production (largest waste),

2. waste of time on hand (waiting),

3. waste of transportation,

4. waste of processing itself,

5. waste of stock at hand,

6. waste of movement,

7. waste of making defective products.

According the authors Salem and Zimmer [7], there are five major lean principles that are applicable in the construction industry:

- customer focus,

- culture/people,

- workplace standardization,

- waste elimination,

- continuous improvement/built-in quality.

\subsection{Lean production management}

The aim of each company is to eliminate the mentioned waste in the manufacturing process. There is the opportunity for the implementation of lean production management to the management philosophy and vision of the company.

The lean management makes it possible to obtain a product that is adapted to actual demand using the minimum amount of resources and therefore minimising the cost, with the appropriate quality and very high speed of response. Since the production system must produce in accordance with demand, it cannot resort to economies of scale by dealing in large batches, as in the case of conventional management systems. In order to attune production to demand and obtain high performance without recourse to economies of scale, lean management is based on two main inherent characteristics [1]:

- Firstly, it operates with the least possible number of activities, thereby obtaining economies that are not economies of scale but rather of resources; for this purpose, all activities that do not add value, called wasteful, must be eliminated, including inappropriate processes, unnecessary carriage, unnecessary movement, stocks of all kinds which would result in increased costs, as well as quality defects and all manner of delays and times, which would be detrimental as regards the quality and response. Furthermore, production that is not attuned to demand is also wasteful (excess production), and avoiding this waste will result in a product or service that is faster, more appropriate and less costly.

- This last aspect is covered by the second main characteristic of lean management, i.e., flexibility, which means that the system must be attuned at all times to the type and volume of production required by demand. 


\subsection{Lean production and integrated design and delivery solutions}

One of the basic attributes of lean production is to create a value for costumer and the to identify of all necessary steps for design, manufacture and supply of products. The appropriate ways for it is an integrated design and delivery solutions (IDDS) of construction projects which present such approaches to the design and realization of construction that will bring the higher efficiency of works and better results for all stakeholders (investors, designers and constructors). It uses a collaborative work processes and enhanced skills of all people involved in the design and implementation of the project, with integrated data, information, and knowledge management to minimize structural and process inefficiencies and to enhance the value delivered during design, build, and operation, and across projects [8]. It allows greater flexibility of design options, work strategies and collaboration with suppliers and trades, which will be essential to meet evolving sustainability targets.

Successful use of IDDS requires improvements in work processes, technology and people's capabilities to span the entire construction lifecycle from conception through design, construction, commissioning, operation, refurbishment, retrofit and recycling, and considering the building's interaction with its environment. One of the requirements for successfully implementing lean production in the construction is the use of IDDS idea in the construction projects.

The vision of International Council for Research and Innovation in Building and Construction (CIB) for future and development of construction industry expect that the construction will be like manufacturing: very lean, very low defect, very efficient, very integrated from the materials to the final product, as the client receives. The construction processes will be more digitally modelled, simulated, controlled and maintained [8]. There will be a true collaboration of distributed teams enabling system and service integration at all levels throughout the building life cycle. Given that use of IDDS can help to implementation of lean construction in practice. IDDS means realization of sustainability ideals. The industry will be informed by performance-based evaluations of the new materials, assemblies and buildings as well as existing ones; progressive owners will require performance at a level which's requires integration and progressive firms will realize this market demand and meet these expectations with the best means; integration of all parts in the projects' design and construction with better performance (documented) delivered. According the vision of $\mathrm{CIB}$, the construction industry will be 30-50\% industrialized construction.

The authors [10] defined the potential benefits of IDDS and lean production for the three groups of construction participants - investors, designers and constructors:

- for investors:

1. easier linking design options to business objectives,

2. improved value and a higher quality product,

3. greater potential for lower cost construction and operation,

4. reduced energy cost of use,

5. facility delivered faster with higher quality so able to begin payback sooner,

- for designers:

1. less rework, minimises iteration,

2. relationships, conversations \& commitments are managed,

3. decisions at last responsible moment, 
4. easier creating excellent green buildings,

5. easier design to target cost,

6. reduced design documentation time,

- for constructors:

1. better integrated design - less rework, lower costs, faster completion,

2. more buildable, logistics considered from outset,

3. relationships, conversations \& commitments systematically managed,

4. greater construction process reliability and cost certainty.

\section{Parallels between lean production and prefabrication in construction}

As we said, the lean production was developed for manufacturing of automotive industry, which is characteristic by an assembly-line production. For purposes of applying the lean production into the construction process, lean production has to be concentrated on the two main conversion activities [10]:

1. design - the main information conversion process,

2. construction - the main materialize conversion process.

The lean production tries to improve those activities and to eliminate all other activities.

The one possible way of lean production in construction industry is to transfer the production of constructions to a specialized facility. In construction is this method of production known as the prefabrication technology. Prefabrication can be defined as a manufacturing process, generally taking place at a specialized facility, in which various materials are joined to form a component part of a final installation.

For most of this century, architects and builders have been seduced by the idea of producing houses in factories [11]. The ideas of Le Corbusier and others resulted in completely new methods of construction, and were to strongly influence design and construction philosophy into the 1960's with the evolution of systems building. Three main principles underpinned the industrialization of construction are standardization, prefabrication and systems building. Standardization of building components was a perquisite for their production under factory conditions (prefabrication) which, together with dimensional co-ordination, enabled the growth of systems building.

Typically prefabrication involves the manufacture of construction parts offsite in a specially designed factory. The two main products of prefabrication are:

- Panels - including ready-made walls, floors and roofs. These are transported to the site and assembled quickly, often within a day. Some panels have wiring and plumbing already inside them, making construction even faster.

- Modules - ready-made rooms or their parts, which can be pieced together to make a whole house or flat but are used most frequently for bathrooms or kitchens, where all the fittings are added in the factory. Also known as 'pods'.

A range of materials is used for prefabrication, the most common being wood, steel and concrete or their combination.

Although, the origins of prefabrication in construction are in 17th century, currently the 
prefabrication is considered as a modern method of construction (MMC). Prefabrication does not involve only the traditional prefabricated reinforced concrete panels and blocks of the panel housing blocks. Current prefabrication is not limited and focused on the assembling the same construction elements. Nowadays, the prefabrication as a modern method of construction allows the architectural and material diversity of particular prefabricated element. Current computer-aided design of products allows to design of construction components of various shapes and material solutions which satisfy also the individual requirements of costumer. It also breaks the myth that the prefabrication is suitable only for projects with the high repeatability construction. An example of this presents the industrialization of house production based on the production by the assembly lines.

\subsection{Industrialized house production - construction process based on the idea of lean production}

In the 1970's, Syohichiroh Toyoda started a housing business (Toyota Homes), trading on the experience in automobile production in terms of quality, reliability and high levels of investment in advanced manufacturing techniques. The success of these houses is due to their application of a technique to a particular type of product in a particular situation, which would be difficult to reproduce elsewhere due to political, more than technical, reasons. Evidence from the 1960's suggests that systems building did not raise overall productivity (except in school building projects), and was rarely cheaper or much quicker than traditional construction techniques. Further, it often resulted in products that were socially unacceptable [11]. This fact confirms the knowledge of the drivers and barriers of prefabrication in construction industry [12].
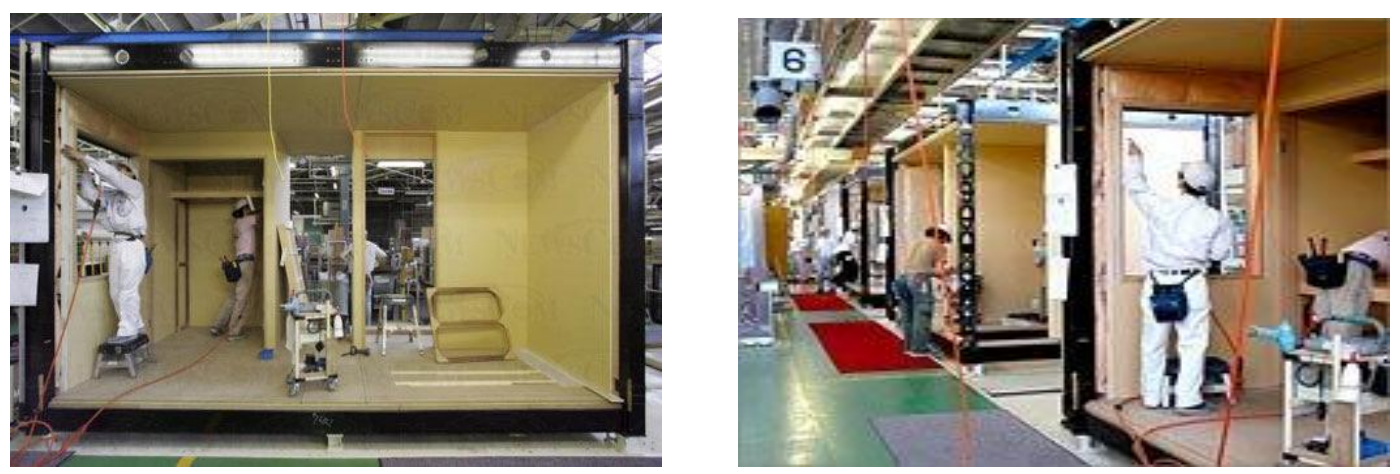

Figure 1: Toyota homes - prefabricated house through lean production in the factory $[13,14]$

Toyota company provides the houses producing by lean production methods for over 20 years, as well. Here is an example of lean management implementation to the construction industry by the prefabricated houses in the practice. Toyota homes are built from six or more prefabricated two story modules in under 45 days [13]. The steel-framed Toyota prefabricated houses leave the assembly factory 85\% complete. The company offers various sizes and designs, with an average family home comprising 12 modules [14]. On the basis of this principle is currently produces of prefabricated houses which reflected the latest trends in the 
modern sustainable construction. In the present, we are witness of design boom in Asian countries. This design boom is connected with the new architectural solutions of prefabricated houses (figure 2).
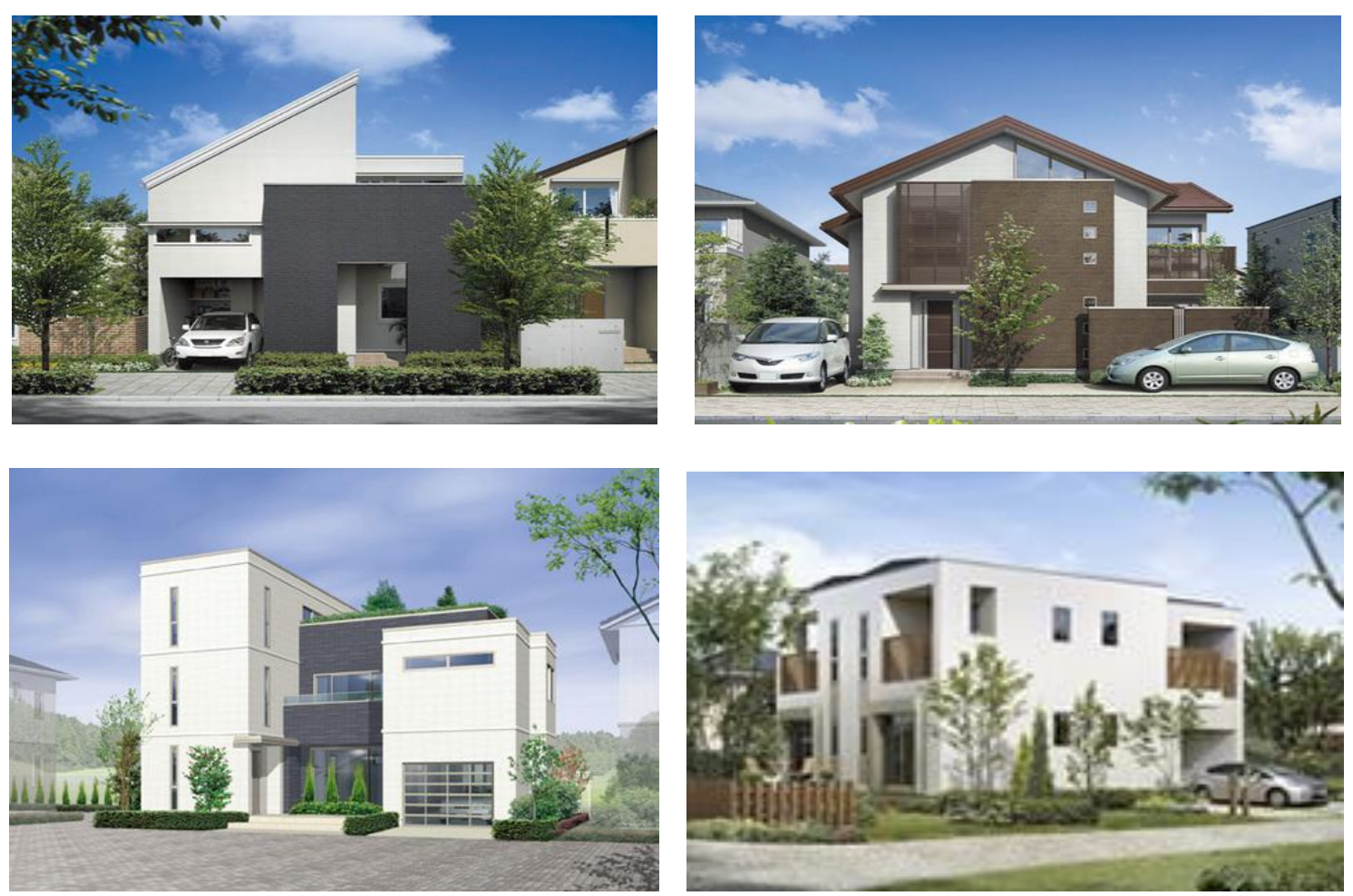

Figure 2: Diversity of architectural solutions of industrialized houses [15]

\subsection{Information flow for lean production in construction industry}

The application of lean production requires the harmonization of working practices as well as the optimization of efficiency and productivity using advanced computer based technology [11].

First of all, we have to provide suitable flow of information in the chain: investor - designer (members of design team) - contractor - investor (owners). The suitable tool for computer aided design presents a Building information modelling (BIM) which integrates the process of design, changes and realization of construction on one platform for the all participants of construction process and for all members of working team. BIM allows to create the objects models (walls, ceilings, stairs,...) and particular details. These objects are characterized in terms of dimensions, materials, but also cost solution and schedule of delivery. This information presents primary information flow to the prefabrication plant about each construction elements. Building information model can be published, synthesized, and augmented with cost and schedule information. Using the BIM, building owners and general contractors can collaborate efficiently, improve predictability, reduce risk, manage cost, and optimize schedules of building projects [16]. These attributes present the elimination of waste according the lean production management, as well. The higher degree of construction design 
and delivery integration presents IDDS which is the appropriate way to improve the information flow within the lean production.

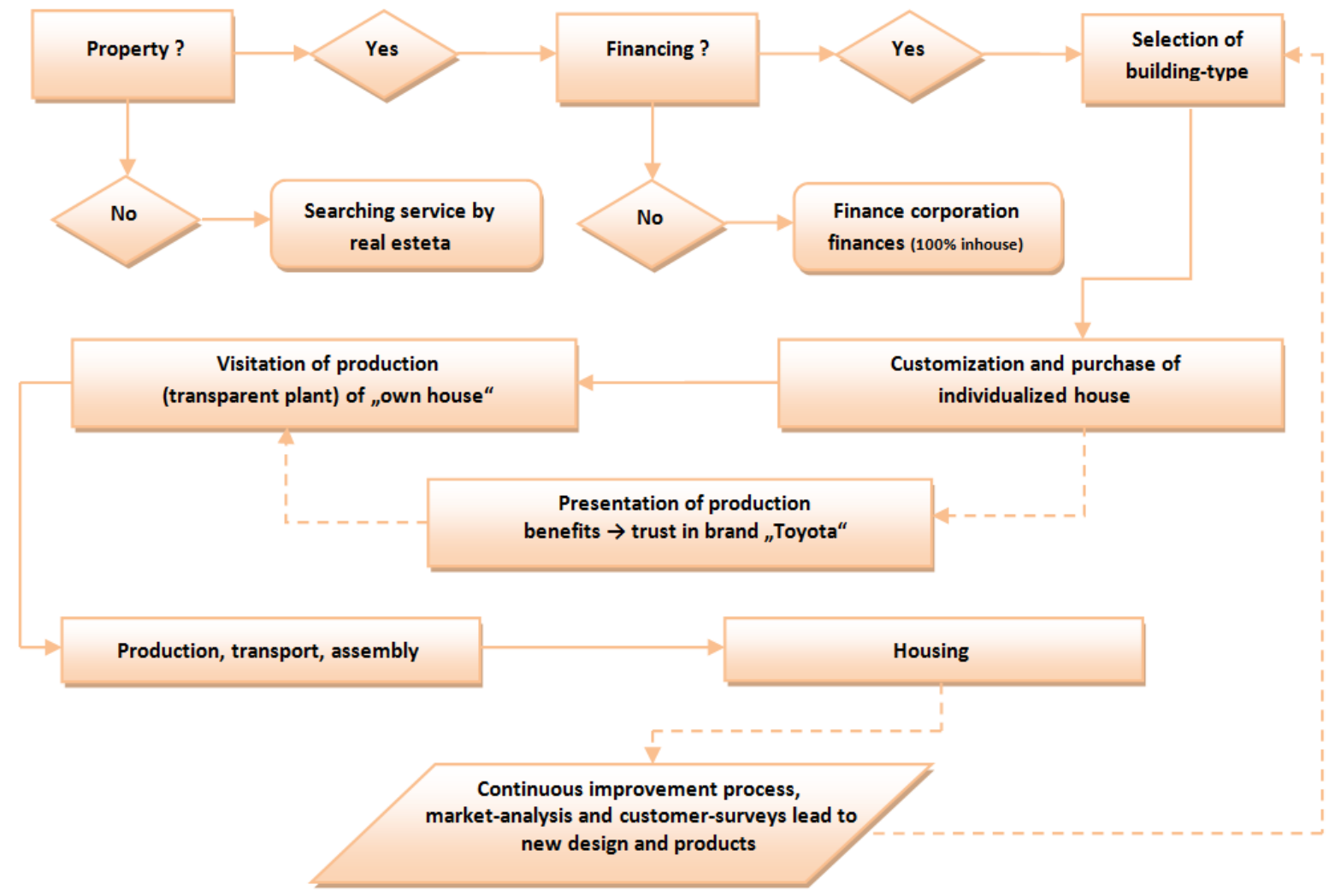

Figure 3: Approach to design of industrialized houses based on information by Toyota company [18]

\subsection{Construction flow for lean production in construction industry}

The prefabricated production of construction elements in the specialized facilities is possible to ensure by the suitable design of building construction elements. There are design of construction elements through the change of information between investor (customer), architect and constructors, what is allowed by the tools of BIM. There are considered the customer requirements according the lean production. There are not produce the overproduction. We can prevent the defects of construction and expressive transportation, because the particular elements are made in the construction plant and transported to the building site.

On the other hand, prefabrication as type of modern method of construction can result in changes to on-site practice and may require different teams of specialist contractors; for example, compare operational needs on site to place large precast concrete components (handling areas, cranes and operators) with the demands of cast in - situ concrete (erection and striking of shuttering, temperature monitoring/control of large pours). To gain the waste 
benefits of MMC and to facilitate the resulting construction process, consideration at the design stage is essential [12].

The realization of prefabricated construction through lean production and the flow of information and construction is on figure 4.

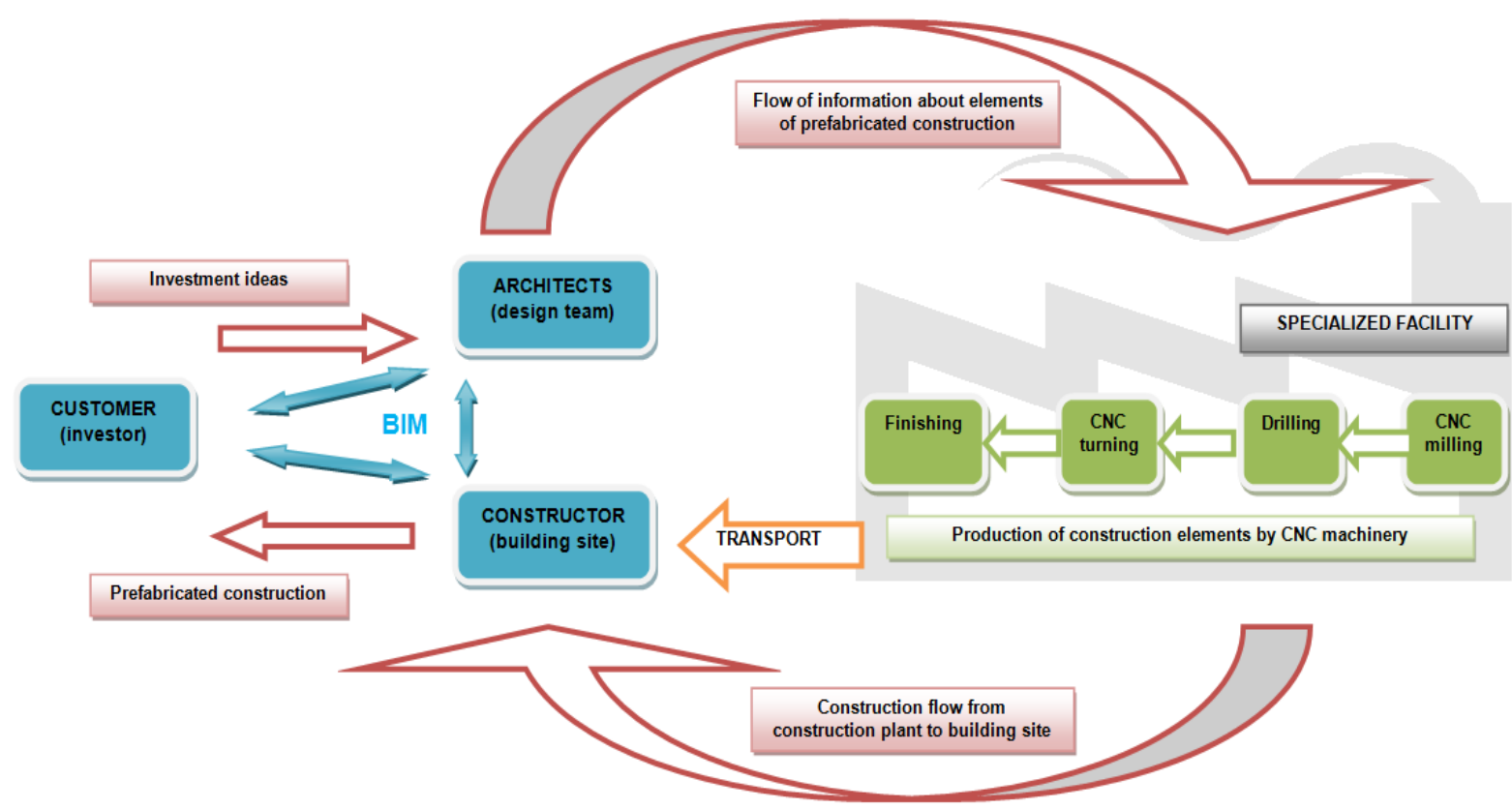

Figure 4: Design and realization scheme of prefabricated construction through lean production

\section{Conclusion}

Nowadays, it is necessary to approach and continuous effort within the industry in order to achieve the objectives sustainable construction and reducing of the environmental impacts of construction. The submitted paper provide a new insights into modern building production where is the created a place to use of idea of lean production. According CIB, the lean production and application of IDDS idea in construction present a vision for future management of construction. First part deals with the characteristic and basic attributes of lean production. Second part of the paper deals with the identification of industrialization and prefabrication as modern method of construction based on the idea of lean production. There are specified the information and construction flows of lean production in construction industry and good practice that already identify and show the increasing of productivity in construction through industrialization.

\section{Acknowledgements}

This paper presents the partial result of project VEGA 1/0840/11 "Multi-dimensional approaches supporting integrated design and management of construction projects". 


\section{References}

[1] Arbós, L. C. (2002). Design of a rapid response and high efficiency service by lean production principles: Methodology and evaluation of variability of performance. International journal of production economics. Vol. 80, 169 - 183.

[2] Haas, C. T., O'Connor, J. T., Tucker, R. L., Eickmann, J. A., Fagerlund, W. R. (2000). Prefabrication and preassembly trends and effects on the construction workforce, USA: University of Texas at Austin.

[3] The Economist. Lean production. (19. 10. 2009) - http://www.economist.com/node/14299730.

[4] Lean manufacturing (10.11. 2012) - http://en.wikipedia.org/wiki/Lean_manufacturing.

[5] Sullivan, W. G., McDonald, T. N., Van Aken, E. M. (2002). Equipment replacement decisions and lean manufacturing. Robotics and computer integrated manufacturing. Vol. 18, 255 - 265.

[6] Ohno, Taiichi (March 1998). Toyota Production System: Beyond Large-Scale Production, Productivity Press.

[7] Salem, O., Zimmer, E. (2005). Application of lean manufacturing principles to construction. Lean construction journal. Vol. 2, $51-54$.

[8] Owen R. (2010) CIB White Paper on IDDS, Salford: University of Salford, UK.

[9] Mossman, A., Ballard. G, Pasquire, Ch. (2010). Lean project delivery - innovation in integrated design and delivery. Architectural Engineering and Design Management. 1 - 28.

[10] Crowlex, A. (1998) Construction as a manufacturing process: Lessons from the automotive industry. Computers and Structures. Vol. 67, $389-400$.

[11] Gann, D. M. (1996). Construction as a manufacturing process? Similarities and differences between industrialized housing and car production in Japan. Construction management and Economics. Vol. 14, 437 - 450.

[12] Spišáková, M. Kozlovská, M. (2011). Reducing of construction waste through new technologies. In Organization, Technology and Management in Construction : 10th international conference, 7 - 10 September 2011(pp. 1 - 14), Šibenik: University of Zagreb, FCE.

[13] Murphy J. (2. 7. 2008). Toyota throws more weight behind its homes unit http://online.wsj.com/article/SB121496449430221935.html.

[14] IBS Modular (29. 3. 2008). Toyota Homes - Live in your next Toyota http://ibsmodular.blogspot.com/2008/03/toyota-homes-live-in-your-next-toyota.html.

[15] Preston, B. (3.7.2008). Toyota looking to expand stylish prefab homes unit http://www.jetsongreen.com/2008/07/toyota-homes-lo.html.

[16] www.vicosoftware.com.

[17] Struková, Z. (2011). Lean production principles in construction projects design and delivery. In Geodesy, architecture and construction 2011: proceedings of the 4th international conference of young scientists, 24. - 26. 11. 2011 (72 -73), Lviv: Publishing House of Lviv Polytechnic.

[18] Schuster, G. Experiences from Japan for industrialized housing production http://www.epaq.eu/db/docs/06_Schuster_EPAQ.pdf. 